\title{
HIGH BACKGROUND AREA FOR RADIATION EDUCATION
}

N. Matsuda ${ }^{1, *}$, N. Fukuda ${ }^{1}$, M. Yamauchi ${ }^{1}$, Y. Tsunoyama ${ }^{2}$, S. Tomita ${ }^{3}$ and M. Kita ${ }^{4}$

${ }^{1}$ Atomic Bomb Disease Institute, Nagasaki University, 1-12-4 Sakamoto, Nagasaki 852-8523, Japan,

${ }^{2}$ Radioisotope Research Center, Kyoto University, Yoshida-Konoe-cho, Sakyo-ku, Kyoto 606-8501, Japan,

${ }^{3}$ Radiation Research and Management Center, Tokyo Institute of Technology, 4259 Nagatsuta-cho, Midori-ku,

Yokohama 226-8501, Japan, ${ }^{4}$ Organization for Research Initiative and Promotion, Tottori University, 4-101

Koyama-cho Minami, Tottori 680-8550, Japan

Received June 13 2003, amended February 10 2004, accepted February 242004

This paper describes our trial experience of the use of high radiation area for radiation education. We used environmental samples collected from the high radiation area in Fukushima prefecture and India, for the practice of radiation measurement and health risk assessment in Nagasaki University Medical School. We also carried out the field monitoring seminar for students in the existing exposure areas in Tottori prefecture and the Yamakiya observatory in Fukushima. Although the evaluation of educational effectiveness is still underway, both types of education appeared attractive for the students mostly due to the exposure from natural environment in our real life which was not achieved by using an artificial radiation source in a classroom.

\section{INTRODUCTION}

Radiation education for students takes an essential part for proper understanding of radiation. In Japan, radiation health risk science program has been newly involved in a model core curriculum of medical students by the Ministry of Education, Culture, Sports, Science and Technology (MEXT). In addition, the Nuclear Regulation Agency of Japan has started a supporting program for radiation education of students to develop human resources for nuclear regulation. One of the common goals of these programs is to attain the ability to assess exposed dose and the consequent health risk properly. Several methods are available for education including lecture, practice, video instruction and elearning. Among them, the practice of radiation measurements attracts the attention of students because they can easily realize that radiation can be detected and all of us are exposed to background radiation. Here we report the use of environmental samples from high radiation area for two different types of education, i.e., radiation risk education in Nagasaki University Medical School, and the free-for all type field monitoring seminar in Misasa-spa radiation springs containing high concentration of radon, in Ningyo-pass uranium mine, and in Fukushima radio-ecological observatory in Yamakiya.

\section{MATERIALS AND METHODS}

\section{Education in medical school}

We used 12 environmental samples, including 7 samples of soil, 2 samples of moss, a sample of dry leaves, a

*Corresponding author: nuric@nagasaki-u.ac.jp sample of gutter mud, and a filter of air exhaust line, collected from 8 different places of Fukushima prefecture after the nuclear power plant accident. Additionally, 3 samples of beach sands were collected from Chinnavilai in Manavalakurichi Town Panchayath, Kanyakumari District, Tami-Nadu, India, which were used as samples from the naturally occurring high background radiation area [1]. Radionuclides involved in those samples, such as Cs-137 and Cs-134 in Fukushima samples and Ac-228 and Th-228 in TamilNadu samples, were analyzed by a HPGe detector (GMX30-70, ORTEC International Inc, Oak Ridge, TN, U.S.A.) coupled with a multi-channel analyzer (MCA7600, Seiko EG\&G Co., Ltd., Chiba, Japan) and then the expected effective doses of residents living in that area were calculated according to the procedure E3 of the IAEA TECDOC 1162 [2]. This procedure enables us to estimate external dose and committed dose from inhalation (resuspension) resulting from remaining on contaminated ground for the period of concern. The fraction of time spent indoors (occupancy fraction) and a shielding factor were considered as 0.667 and 0.4 , respectively. The distribution map of contaminated soils was also drawn.

\section{Free-for all type field monitoring seminar in high radiation area}

In field monitoring seminars, radiation detectors we used were TCS-172B ( NaI(Tl)-scintillator, Hitach Ltd., Tokyo, Japan), PDR-303 (semi-conductor detector, Hitachi), and NHL-4 (semi-conductor detector and $\mathrm{Cs}(\mathrm{Tl})$ scintillator, Fuji Electric Co. Ltd., Tokyo, Japan) for environmental $\gamma$-ray survey, and TCS-1319H (plastic scintillator, Hitachi) for $\beta$-ray survey. Gamma-ray energy spectrum was analyzed in situ by EMF Model

1 
211 (CeBr3 scintillator, EMF Japan Co., Ltd., Osaka, Japan) . Personal exposure dose was measured by PDM127B and D-shuttle (Semi-conductor detector, Chiyoda Technol Corporation, Tokyo, Japan).

\section{RESULTS}

\section{Education in Medical School}

Examples of $\gamma$-ray energy spectrum of a gutter mad in Fukushima and the radionuclides detected in beach sand in Tamil-Nadu are shown in Figure 1 and Table 1, respectively. The calculated effective doses by the exposure to the contaminated ground were within the range from $0.05 \mathrm{mSv} / \mathrm{month}$ to $0.5 \mathrm{mSv} /$ month. Students were asked to evaluate the health risk of residents and to figure out the reason why the radioactive contamination distributes unevenly. The example of evaluation is 'How much do you assess health effect by $0.5 \mathrm{mSv} / \mathrm{month}$, which reaches $1 \mathrm{mSv}$, the dose limit for whole population, by staying for 2 months, and what do you recommend as protective measures?'. The calculation itself is not difficult for medical students so they reached the same answer, but the health risk estimation by them was widely varied. Finally, we discuss the risk for tissue reactions, cancer, genetic effects, and the perception of the risk by the people. The understanding by the students appeared to reach a certain level because we provided them an opportunity of radiation dose evaluation and health risk assessment in real life situations. The effectiveness of education is to be evaluated.

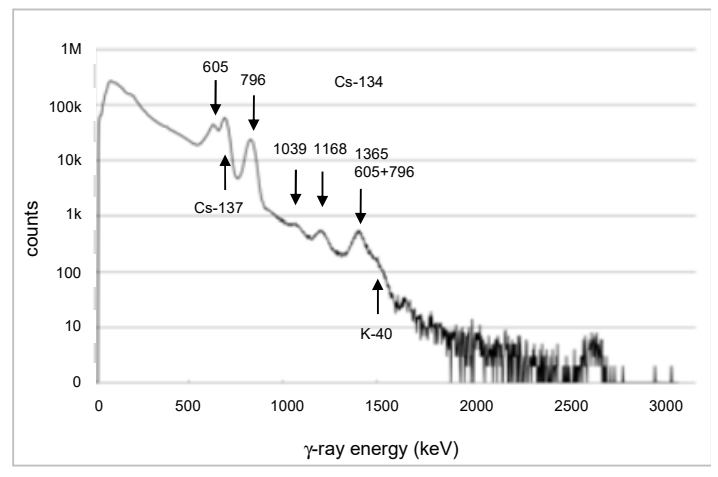

Figure 1. $\gamma$-ray energy spectrum of the gutter mad collected on July, 2014 from the north gate area of the Fukushima Daiichi Nuclear Power Station. Radioactive concentration was 2.3 $\mathrm{kBq} / \mathrm{g}$ and $1.0 \mathrm{kBq} / \mathrm{g}$, respectively.
Table 1. Analysis of radionuclides in the beach sand from Chinnavillai, Tamil-nadu, India and Nagasaki.

\begin{tabular}{cccccc}
\hline \multirow{2}{*}{ Nuclide } & \multicolumn{5}{c}{ Radioactivity (Bq/g) } \\
\cline { 2 - 6 } & \multicolumn{5}{c}{ Chinnavillai $^{\text {Nagasaki }}$} \\
\cline { 2 - 6 } & spot-1 & spot-2 & spot-3 & spot-1 & spot-2 \\
\hline Thorium series & & & & & \\
Ac-228 & 35.40 & 26.90 & 40.80 & 0.00058 & 0.0037 \\
Th-228 & 38.60 & 33.70 & 43.70 & N.D. & N.D. \\
Ra-224 & 33.90 & 22.70 & 37.40 & N.D. & N.D. \\
Pb-212 & 35.10 & 23.70 & 38.70 & 0.00062 & \\
Bi-212 & 40.30 & 25.90 & 40.20 & 0.00133 & N.D. \\
Tl-208 & 11.00 & 7.17 & 11.50 & 0.00014 & 0.0011 \\
\hline Uranium series & & & & & \\
Pa-234m & 12.20 & 12.50 & 15.90 & N.D. & N.D. \\
Ra-226 & 5.69 & 3.92 & 9.34 & 0.0787 & 0.0461 \\
Pb-214 & 4.81 & 2.85 & 4.66 & 0.0047 & 0.0037 \\
Bi-214 & 4.34 & 2.90 & 4.53 & 0.0053 & 0.0036 \\
\hline Actinium series & & & & & \\
U-235 & 0.19 & 0.15 & N.D. & N.D. & N.D. \\
Th-231 & 7.19 & 6.28 & 8.12 & N.D. & N.D. \\
\hline
\end{tabular}

Free-for all type field monitoring seminar in high radiation area

\section{Misasa-spa and Ningyo-pass}

The practical training of field radiation monitoring is effective for understanding environment radiation and might be a trial experience of radiation emergency monitoring. The 2-day course field monitoring seminar was held in November 2017 and the 13 students attended from entire Japan by free application. They major in various fields such as geochemistry, applied physics, environmental biology and disaster medicine. The students with 10 teaching staffs gathered together in Misasa-spa, where the radon concentration of spring water was $331 \mathrm{~Bq} / \mathrm{L}$ as the average of several reports [3]. The environmental radiation was measured by walking around the district with a detector given to each student. The highest dose rate was $1.13 \mu \mathrm{Sv} / \mathrm{h}$ observed on the surface of a spring water basin at the site of Chozusha. Discussion on the results, coupled with the lectures and students' presentations, were set as an indoor seminar after the field monitoring. On the second day, all the students moved to the Ningyo-pass uranium mine and visited the Ningyo-toge Environmental Engineering Center. The history of technology development for the use of uranium mine and the process of risk communication in local government and residents were introduced. Students were exposed to a very special field of science that they had not encountered and developed a strong interest in radiation after the seminar, which may be their motivation and a trigger of future study. 

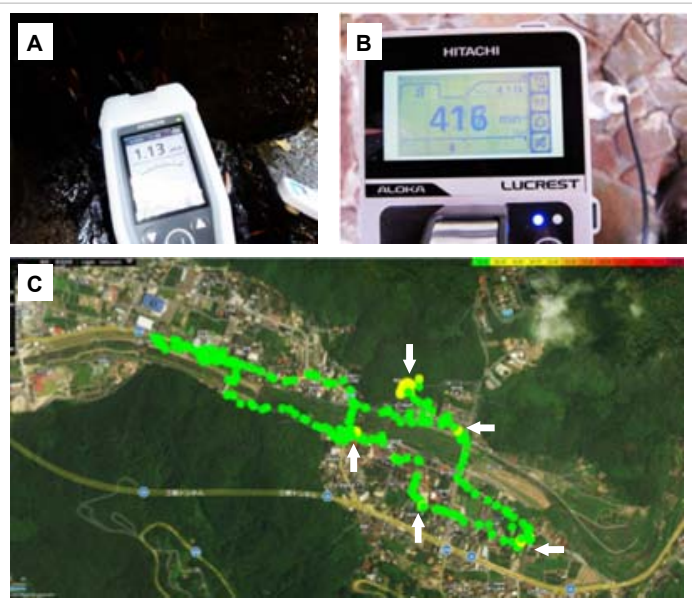

Figure 2. Walking survey in Misasa-spring area. Radiation dose rate(A) and surface radioactivity(B) at Chozusha of Misasa Shrine are shown. In a walking survey $\operatorname{map}(\mathrm{C})$, arrows indicate the places with dose rate higher than $0.1 \mu \mathrm{Sv} / \mathrm{h}$.

\section{Fukushima radioecological observatory in Yamakiya}

The radioactive contamination is slowly decreasing in Fukushima; however, $7.0 \%(42)$ of total monitoring stations(598) in Fukushima prefecture demonstrate the environmental dose higher than $1.00 \mu \mathrm{Sv} / \mathrm{h}$ as of October 16, 2018 [4]. In addition, many places remain contaminated because of difficulties of decontamination such as a forest. The Yamakiya forest observatory site is established by Fukushima University and is located 35 $\mathrm{km}$ northwest of the Fukushima Daiichi Nuclear Power Station [5]. By the courtesy of Fukushima University Institute of Environmental Radioactivity (IER), we held a 2-day course field monitoring seminar in August 2018. Nineteen students and 9 radiation professionals from various areas of Japan joined in this seminar.

The seminar was started by lectures in the Fukushima Center for Environmental Creation and IER, covering the topics on lessons learned from the radiological disasters by atomic bombing and NPP accidents, radiation emergency monitoring measures, and the ongoing radioecological investigations in the Yamakiya observatory site. Then all the attendants moved to Yamakiya and started measuring radiation dose rates and surface contamination freely in the site (Figures 3, 4 and 5). Soil samples were collected for future analysis. The written survey to the students after the seminar showed that they were most interested in field monitoring practices although other three topics were also interesting, and that their interest on radiation was enhanced.

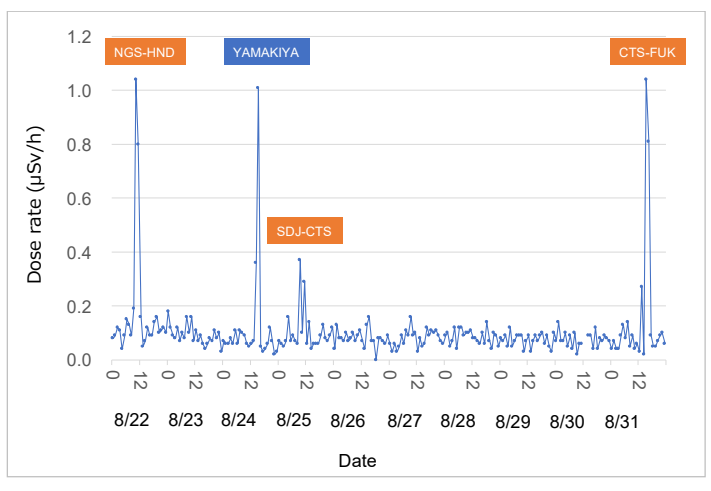

Figure 3. Chronological changes of dose rate $(\mu \mathrm{Sv} / \mathrm{h})$ in the period of before and after Yamakiya field monitoring. At the indications of NGS-HND, SDJ-CTS and CTS-FUK, X-ray examination was carried out at the airport.

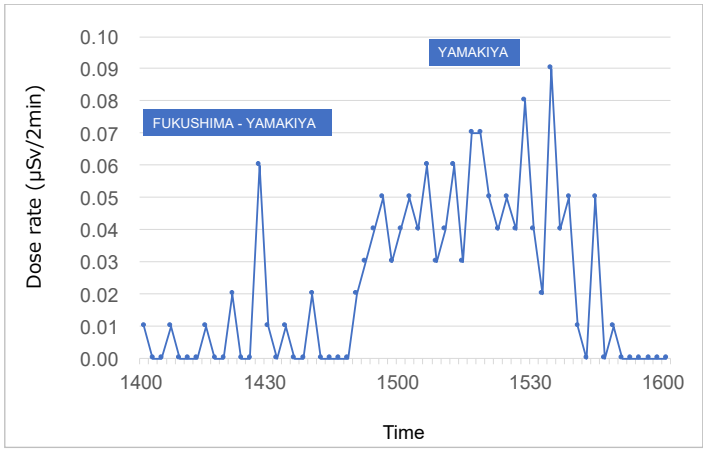

Figure 4. Chronological changes of dose rate $(\mu \mathrm{Sv} / 2 \mathrm{~min})$ in Yamakiya field monitoring. Students left Fukushima at 14:00, arrived at Yamakiya ay 14:45, and then moved into the forest.

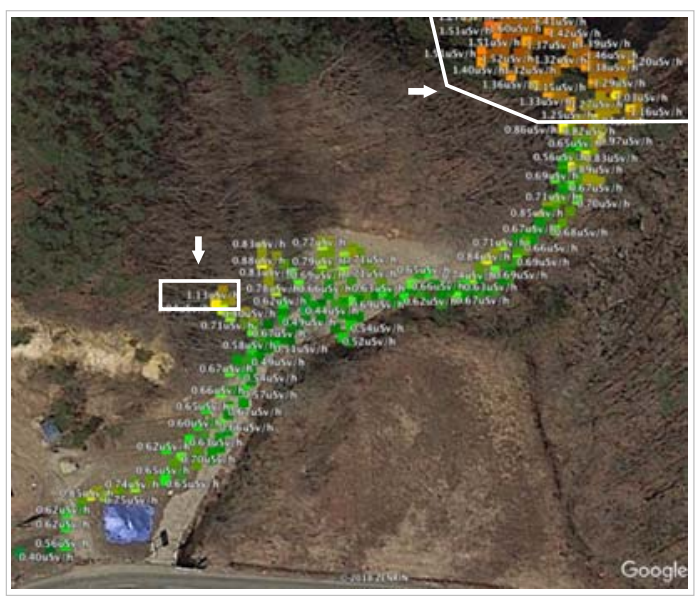

Figure 5. Walking survey in Yamakiya observatory site. Radiation dose rate higher than $1 \mu \mathrm{Sv} / \mathrm{h}$ was detected at the sites indicated by arrows. 


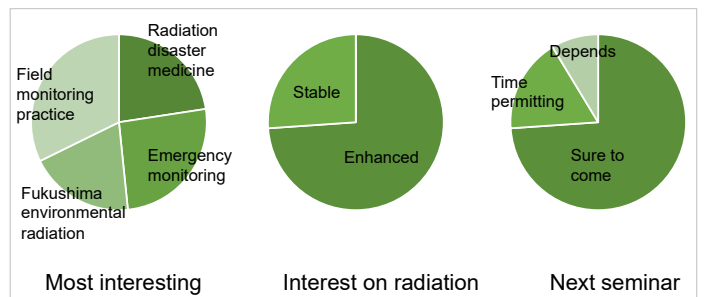

Figure 6 . Responses of students after the seminar collected by written survey.

\section{DISCUSSION}

Regarding the relationship between high background area and radiation education, Sohlabi has recommended establishment of the natural radioactivity park in Ramsar and surrounding areas in Iran for research and education purposes. The area would be a natural radioactivity museum for students [6]. Our trial experience of the use of high background area for radiation education is in line with this. We have collected radioactive samples from the high background radiation area and used them for the practice of radiation measurement in radiation health risk science program in Nagasaki University Medical School. We have also carried out the field monitoring seminar for students with various majors in the existing exposure areas, Misasa-spa and Ningyo-pass in Tottori prefecture and the Yamakiya observatory in Fukushima prefecture. Both types of education appeared attractive for the students mostly due to the exposure from natural environment in our real life which was not achieved by using an artificial radiation source in a classroom. The evaluation of effectiveness of these education trials are now underway and will take another one or two years.

\section{ACKNOWLEDGEMENTS}

The education programs reported here were financially supported by the problem-solving development program for high-level medical professionals by MEXT, the human resource development project for nuclear regulation by Nuclear Regulation Agency of Japan, and JSPS KAKENHI Grant Number 16H03062.

\section{REFERENCES}

[1] Matsuda N, Brahmanandhan GM, Yoshida M et al. Background radiation and individual dosimetry in the costal area of Tamil Nadu, India. Radiat Prot Dosimetry. 146: 314-317, 2011.

[2] International Atomic Energy Agency. Generic procedures for assessment and response during a radiological emergency. IAEA-TECDOC-1162: Procedure E3, 2000.
[3] Horiuchi K, Minowa H, Yoshizawa Y. 100 years of radon research of Misasa hot springs. J Hot Spring Sci 64: 409-421, 2015.

[4] Radiation monitoring reports. Fukushima prefecture.

http://www.pref.fukushima.lg.jp/sec_file/monitorin g/kakuchihou.pdf. viewed on October 16, 2018.

[5] Fukushima Radioecological Observatory in Yamakiya. https://www.radioecologyexchange.org/content/fukushima-radioecologicalobservatory-yamakiya. Viewed on October 18, 2018.

[6] Sohrabi M. World high background natural radiation areas: Need to protect public from radiation exposure. Radiat Meas. 50: 166-171, 2013. 